\title{
Identification, Classification and Zooarchaeology
}

\author{
Jonathan C. Driver ${ }^{1}$ \\ Author Address: ${ }^{1}$ Department of Archaeology, Simon Fraser University, Burnaby, BC V5A 1S6 driver@sfu.ca
}

Received: June $18^{\text {th }} 2011$

Volume 2:19-39

Published: August $9^{\text {th }} 2011$

(C) 2011 Society of Ethnobiology

\begin{abstract}
Identification of preserved biological materials is often regarded as a skill which has little to do with analysis and interpretation. This paper argues that in zooarchaeological studies-here with particular reference to vertebrate remains-identification procedures deserve more detailed consideration, because these procedures have a significant effect on the results of faunal studies. It is suggested that most identifications are made within a system of usually unspecified rules which vary from one analyst to another. Improvements in comparability between faunal studies will result if these rules are considered before beginning an analysis, and if the rules are made explicit in publications.
\end{abstract}

Key Words: zooarchaeology, methods, identification

\section{Introduction}

Most archaeological studies employ typologies as descriptive and analytical devices. The conscious use and analysis of typologies dates from the publication of Krieger's (1944) paper, and a large, complex, and sometimes acrimonious literature has been devoted to typology in general and artefact typology in particular (Hill and Evans 1972; Whallon and Brown 1982). In spite of the continuing typological debate there would appear to be a general consensus that typologies are artificial devices designed to expedite research in specific areas (Hill and Evans 1972; Hayden 1984) and that "types of types" (Steward 1954) exist.

Typological debates continue in many sub-disciplines of archaeology, and these generally concern the appropriateness of certain typologies for solving certain archaeological problems. For example, typologies of microchipping have been called into question by Vaughan (1985) on the basis of experiments which suggest that the correlation between microflake form and the material worked by the stone artefact is not as good as once thought. Similarly, the utility of some typologies of lithic debitage have been questioned by Sullivan and Rozen (1985).

Editors Note: Jonathan Driver was invited to re-publish this paper by the EBL editors. In addition, we have invited several commentaries on this important methodological paper from leading zooarchaeologists. This article originally appeared in Circaea (http://www.envarch.net/ publications/circaea/index.html), the journal of the Association for Environmental Archaeology, which is now known as Environmental Archaeology (http://www.maney.co.uk/index.php/journals/env/). This article is reproduced with the permission of the Association for Environmental Archaeology.
There has been relatively little debate about typology in the analysis of animal remains from archaeological sites. This is because most zooarchaeologists have assumed that the system with which they describe specimens may be imported intact from zoology. As a result most methodological developments have been in the interpretation of organic remains rather than in their classification and description. The one important exception to this is the discussion concerning the identification of cut marks and breakage patterns on bone (e.g., Behrensmeyer et al. 1987; Binford 1981; Johnson 1985; Morlan 1986; Shipman 1981). Typologies of these phenomena are concerned with the identification and classification of humanly produced modifications rather than the identification of the faunal element on which they are found. They therefore resemble artefact typologies, and share all the problems and advantages inherent in such methods.

In this paper I will briefly consider the theory of identification, then examine the use of classificatory systems to describe and "identify" faunal specimens from archaeological sites. It will be suggested that zooarchaeologists should consider their identification systems more carefully in order to increase the degree of standardisation of data presentation and reduce the possibility of interpretive error resulting from misapplication of identification methods. Examples will be drawn largely from vertebrate zooarchaeology. It is in this field that problems of identification are most likely to occur, because zooarchaeologists are generally concerned with identifying elements or parts of elements of complex endoskeletons. Analysis of other 
animal remains, such as molluscs or insects, is usually concerned with identification of relatively complete shells or exoskeletons. This is not to say that many of the problems discussed below will not occur; however, the problems are probably less acute than in the field of vertebrate zooarchaeology.

I should point out at the start of this paper that I have deliberately avoided discussing "case studies" which I consider to be examples of poor identification procedures or data reporting. Most zooarchaeologists, including myself, have made errors of the types discussed below. It will not serve any purpose to select a few examples from the many to illustrate the points made here.

\section{Identification, Classification, and Typology}

The initial stage of any zooarchaeological analysis is to group specimens into meaningful categories. Although this may appear to be similar to the creation of artefact typologies, which also group objects into meaningful groups, there are differences between the two processes. These differences stem from the distinction which must be made between classification and typology on the one hand and identification on the other. Classification is the process of grouping objects or other phenomena into groups based on similarities and differences (Hill and Evans 1972, 233). Typology is a special form of classification, in which phenomena are assigned to the same type if they share consistent patterning of attribute states (ibid.). Biologists have distinguished identification from classification (Sneath and Sokal 1973, 3), noting that identification is the assignation of an organism to a previously established classificatory system.

Archaeologists who study artefacts may wish to use previously established typologies and "identify" their artefacts by reference to those systems. However, they are always free to modify such typologies or to develop new typologies if existing systems are inadequate for their research design. As a result, there may be debate about the relative merits of different typological systems to assist in the solution of the same research problem. Alternatively, one may apply two completely different typologies to the same artefact assemblage if one wishes to investigate two different areas of human behaviour. For example, typologies of ceramics or lithics which are useful for constructing culture history may be inappropriate for analysing site function.

Archaeologists, who study animal remains, or any other largely unmodified organic material, generally organise their specimens into groups by a process of identification. No matter what the research orientation, it is commonly assumed that the initial step of a faunal analysis is to group species according to well-defined attributes preserved in chitin, shell, bone or teeth. This accounts for the widespread establishment of comparative collections and the publication of identification guides and keys. Most zooarchaeologists believe that pre-existing classificatory systems can be employed in the analysis of organic remains. This view is further enforced by fairly frequent pleas for standardisation of data reporting in zooarchaeology (e.g., Clason 1972; Grigson 1978; Driver 1983), such standardisations being impossible without a general agreement that there is a single appropriate classificatory system.

This attitude is certainly reasonable, and many specimens can indeed be grouped using two biological schemes. The first of these is the standard binomial nomenclature; the second is a fairly well standardised system of anatomical description. Using these systems "Bison bison left femur" is likely to be well understood throughout the English speaking world and (with one translation) throughout the entire world. This stands in contrast to artefact typologies which, in some areas, have become so cumbersome as to become almost unworkable, and which contain few standardised terms acceptable in more than one language.

If one accepts some of the assumptions (discussed below) inherent in the classification "Bison bison left femur" then this is a reasonable way of describing faunal remains. In fact, most vertebrate remains can be described quite precisely by three variables-species, element, and part of element, the latter following a system such as Brumley's (1973) butchering units or Watson's (1979) diagnostic areas. Some specimens may be described further, using categories such as age, sex or pathological condition, but these are usually a distinct minority of the entire assemblage.

Are faunal identifications a form of typology? In some ways they do resemble artefact typologies. Bones are grouped by considering a variety of attributes, with multiple attribute states. The groups are exclusive, and can be defined by non-random associations of attribute states. However, there are important differences between a system of bone identification and artefact typology. The binomial system assumes phylogenetic relationships between animal groups, which is not the case with artefact typologies. The binomial system is hierarchical while many artefact typologies are not. The basic unit of zoological classification - the species - is essentially defined by its reproductive behaviour, while the basic unit of typology - the type - does not exist as a population and has no capacity for perpetuation. 
Finally, modern artefact typologies are designed to solve specific research problems, while zoological systems of classification are often used as descriptive referents in research which does not deal with phylogeny.

\section{Methods of Identification and their Effects on Bone Groups}

Of the three major attributes defined above (taxon, element and modification), the third will not be discussed in this paper, as it is often describing an artificially induced condition of the bone, and consequently most zooarchaeologists have to be explicit in developing non-zoological typologies to describe bone fragments or other aspects of bone modification. Identification of specimens is essentially a matter of grouping specimens by taxon and element.

The methods by which bone fragments are identified ought to be relatively simple. First, it is necessary to identify the element represented by the complete bone or bone fragment. Unless one can identify the element represented, it is usually impossible to justify identification of taxon. It may be possible, using such criteria as bone thickness or surficial characteristics to identify some fragments to the class level without first identifying the element. For example, long bone fragments with cortical bone thicknesses over a few millimetres are unlikely to be anything except mammals (unless one is working in an area with large reptiles or large flightless birds), and many cranial bones of fish display distinctive surficial characteristics which distinguish them, as a class, from other vertebrate classes. However, I strongly suspect that in many cases the assignment of bone fragments to categories such as "unidentifiable mammal" or "unidentifiable bird" is the product of wishful thinking. This is particularly likely in the case of birds, where size ranges and cortical thickness of bone fragments frequently overlap with the smaller mammalian species.

It is worth emphasising that assignation of any bone fragment to all but the most general taxonomic group cannot be undertaken without identification of the element. Generally, once one considers specimens below the level of the class, there are no readily observable features of the gross morphology which permit identification of the taxon without prior or concomitant identification of the element. Terms such as "small ungulate long bone fragment" are meaningless, although they are sometimes encountered in the zooarchaeological literature. If the features on the fragment are sufficient for identification as a small ungulate (as opposed to a medium-sized carnivore, for example), then they will certainly be sufficient to identify the element from which the fragment derives.

The second stage of identification is to assign the identified element to a taxonomic group. Such identifications may range from very general (e.g., the order or family) to the particular (species or subspecies). Regardless of the specificity of the identification, it follows that the identification guarantees distinction from other taxa at the same level of specificity. Thus, the identification "Canidae" should guarantee that the specimen could not belong to any other mammalian family, such as Felidae or Cervidae. Similarly "Canis lupus" implies that no other members of Canis, such as C. familiaris or C. latrans are represented.

The use of such a classificatory system depends upon the following:

1. Zooarchaeologists employ the existing binomial nomenclature used by zoologists.

2. Identification to the given taxonomic level is justified by the methods employed.

These principles are investigated further below.

\section{Use of Binomial Nomenclature}

The International Code of Zoological Nomenclature (ICZN) provides rules for the classification of animals by order, family, species etc. and, like many artefact typologies, is a way of simplifying an incredible array of diversity (Jeffrey 1977). It is organised in such a way as to suggest degrees of relationships between phenomena; for example, animals of the same genus are thought to be more closely related (i.e., they diverged more recently from a common ancestor) than other members of the family to which the genus belongs. The zoological classification is also an artificial classificatory device, as are archaeological typologies. With the possible exception of the species, all other hierarchical levels of the system are imposed by zoologists, rather than by nature.

One must remember that, because the binomial system defined by the ICZN is artificial, there are other ways to develop classifications of animals. For example, one could describe groups based on diet, locomotion and size, such as those used by some paleoecologists (e.g., Van Couvering 1980). The emphasis in zooarchaeology, palaeontology and palaeoecology on identification of taxonomic groups defined by the ICZN is because of the general belief that identification of the species allows one to infer a wide range of other information, including tolerances to a variety of climatic conditions, habitat types utilised, and various behavioural traits (e.g., social behaviour; migrations 
etc.). The reason for the continued use of the binomial system of nomenclature is probably because most other possible classifications of vertebrates will operate at a more general level than the species, and identification of bones using standard zoological categories allows them to be regrouped into other classificatory schemes if required.

In most cases the use of the binomial system does not cause problems, but one must recognise that zooarchaeologists frequently modify the system, usually by recognising size classes which cross-cut established taxonomic divisions. The most widely used example of this would be a designation such as "large ungulate". Such an identification for Late Pleistocene/Holocene faunas of Canada might include bones of horse, bison, musk ox, camel, wapiti and moose, from two separate orders and four separate families. From the same fauna one might also recognise "small ungulates", which could include deer, caribou, sheep, mountain goat, pronghorn antelope and possibly even saiga antelope; in this case the taxonomic category includes two families from a single order. Thus, while bones with many diagnostic features might be assigned a taxon based on established zoological classifications, bones with fewer diagnostic features may be "identified" using a system which groups specimens from separate lineages into a single category based on an attribute (size) which is not relevant to the zoological system. Thus, some cervids (moose, wapiti) are separated from other cervids (deer), but grouped in the same "large ungulate" category as bovids, camelids and equids. This is somewhat analogous to the provisions in the International Code of Botanical Nomenclature which allow the category "form-genus" to describe superficially similar fragmentary plant fossils which may derive from a variety of different families (Jeffrey 1977, 40).

The implications of this methodology are probably not critical to zooarchaeology, although one wonders whether it is really worth making these types of identifications, as virtually no inferences or deductions are ever made from such information. However, as will be discussed below, if one begins to make assumptions about which species are really represented in these very general taxonomic categories, the potential interpretive value increases and new problems arise.

\section{Identification Systems}

As a zooarchaeologist, one is occasionally stopped in hallways or, more disconcertingly, in conference receptions and asked to identify a specimen. After a few instances of embarrassingly implausible identifications, one learns to ask some critical questions before making a pronouncement. "Where does it come from?" and "How old is it?" are the two I have used most frequently. Such preliminary questions reveal something rather interesting about our identification methods-we frequently rely upon the context of the specimen to aid our identifications. It would appear that our methods do not simply depend on recognising "diagnostic" characters on bone fragments, but also on other assumptions which are rarely stated. These assumptions are worth examining in some detail.

Assumption 1: Although taxonomic groups are defined by a host of characteristics, most of which are not preserved archaeologically, single bones exhibit sufficient diagnostic characteristics to allow identification, frequently to the species level.

This assumption is the basis for zooarchaeological identification. Yet very few bones in the post-cranial skeleton are diagnostic of the species if one has to select one species from the entire animal kingdom. For example, the presence of a large bovid femur fragment on a 3000 year old site from the Canadian plains virtually guarantees the identification Bison, and in many cases analysts will identify Bison bison. However, on a historic period site from the same area, many femur fragments would be indistinguishable from domestic cattle, and would be recorded as Bos/Bison. What zooarchaeologists really mean when they identify a bone fragment is that, given our knowledge of what animal species are likely to have been found in an area during a particular time period, one can identify a fragment based on a combination of size and morphological characteristics. In the above example, the bison femur fragment is probably not distinguishable from those of European bison or some African and Asian bovids. However, given the likely geographic range of fauna, the possibility of there being an Old World bovid in the assemblage is considered so unlikely as to be dismissed.

Another problem associated with this assumption is the concept that the zoological taxonomy is immutable, whereas in fact it is in a constant state of revision. For most vertebrate zooarchaeologists this is not a major problem, because revisions tend to be rare and minor. However, it can lead to some embarrassingly over-confident identifications. For example, until recently ornithologists identified two species of flickers in western North America, the redshafted flicker (Colaptes cafer) and the yellow-shafted flicker (C.auratus). These are now considered as subspecies of a single species, the common flicker (C.cafer). If one reads zooarchaeological reports from the 1960s and 1970s one can find bones of both 
original "species" identified. One suspects that, in reality, the skeletons of these two types of bird exhibit so much overlap that one cannot separate them, and certainly today few people would attempt to separate bird subspecies on osteological characters. The fact that the two types were originally divided into separate species probably produced a state of over-confidence in zooarchaeologists, who felt that osteological differences ought to be found. Today no one attempts to make the distinction which was made a decade or so earlier, because the taxonomy has changed, not the birds.

Assumption 1 therefore requires some modification. Bones are not identified solely by their morphology and size. Rather, a great many possible species are excluded as candidates by virtue of their position in time and space. Furthermore, species which can be separated by zoologists are not necessarily separable on the basis of osteology.

Assumption 2: The methods for identification are sufficiently well tested that one does not need to justify most identifications, except in relatively rare circumstances.

In most zooarchaeological publications there is little discussion of identification methods. Perhaps zooarchaeologists feel that their methods of identification are so easy to use that the methodology requires little discussion. Perhaps they rely to so great an extent on "experience" that they cannot describe their methods. Generally, discussion of identification methods is confined to relatively rare species, when it is important to demonstrate that the identification is justified. In addition to personal experience, zooarchaeologists use three methods for identifying fragments:

a) comparative collections

b) published guides or keys

c) measurement systems

The use of comparative collections is widespread, and probably forms the basis for most identifications made by zooarchaeologists. However, most comparative collections (including the one I use) are really inadequate for their intended purpose. Returning to an earlier example, the identification "Bison bison left femur" is usually arrived at through the following type of mental process: "clearly a large ungulate, based on morphological characteristics and size; perissodactyls can be eliminated on the basis of morphology, so it must be an artiodactyl; the only artiodactyls of this size on the Canadian plains at $3000 \mathrm{BP}$ are bison, moose and wapiti; specimen was compared with an old male bison which died in a zoo, a juvenile moose donated by a game farm, and a mature female wapiti culled from a national park; characteristics most resemble the bison". While this may exaggerate the deficiencies of comparative collections, there are few which contain sufficient numbers of specimens to cover age and sex variation, individual variation, or variation resulting from life in different habitats. Most identifications using comparative collections are therefore "best guess" approximations, usually based on inadequate comparative samples.

The use of identification guides and keys also poses problems. A key is a formally laid out system of identification, usually organised in such a way that presence or absence of characteristics can be used to identify a species. Keys usually have a branching form, so that one begins by looking for features characteristic of gross taxonomic groupings, and then proceeds to finer divisions (Pankhurst 1978). Such keys are rare in vertebrate zooarchaeology or paleontology, because each species possesses hundreds of bones, and bones are generally found as fragments. Consequently, a formal key would be required for each part of each element of the skeleton, or at least for those areas generally considered most useful for separating taxonomic groups. While attempts to do this have been made (e.g., various keys in Gilbert et al. 1985), most published aids to identification cannot be described as keys. In most cases they are usually collections of illustrations, sometimes with notes discussing diagnostic characteristics (e.g., Gilbert 1980; Olsen 1964, 1968; Schmid 1972; Smith 1979). As I have suggested (Driver 1987) the existence of such guides is somewhat anomalous. For the frequently occurring species in an area, one can anticipate that most zooarchaeologists will have access to comparative collections which contain those species, and "hands on" inspection is likely to be better than illustrations for the purposes of identification of fragments. For rare species, on the other hand, it is surely better to take the specimens to a comparative collection which contains the species than to rely on an illustration to identify a rarity. The only guides which have any real value to zooarchaeologists are those which summarise the results of observations of large numbers of specimens and discuss distinctive diagnostic characteristics which consistently occur (e.g., Olsen 1960; Brown and Gustafson 1979; Lawrence 1951). Such publications are relatively rare, and even those which are based on observations of many specimens rarely provide information on how many specimens of each species were consulted or the locations from which specimens were obtained. Nevertheless, they are quite important as a supplement to a comparative 
collection, because they point out consistent diagnostic differences between morphologically similar species.

Most zooarchaeological identifications are made through a combination of comparative collections and illustrated guides, generally used in a complementary fashion. Good illustrated guides will be the result of examination of many specimens, and should partly solve the problem of most comparative collections-insufficient representation of intra-species variation. The comparative collection is essential for the identification of fragments, and for examining details of bone morphology.

Measurement systems of varying degrees of complexity have been used by zooarchaeologists. At the most simple level, all analysts use gross size to eliminate certain taxa from consideration. Thus, to return to the example of the bison femur, sheep is excluded, on the criterion of size rather than morphology, because both sheep and bison share many morphological features. More complex systems of measurement involve taking multiple measurements on single specimen, and are generally only used to separate closely related species. These measurements may be compared using a bivariate plot (e.g., Davis 1987, figure 1.12) or by using multivariate statistics (e.g., Morey 1986). While such methods appear to be sound, as they are based upon measurements which discriminate between modern specimens of known taxonomic affiliation, they can be misleading. Many modem species exhibit considerable geographic variation and, while a system of measurements may discriminate between two closely related sympatric species, it is not necessarily the case that the method can be applied in other regions or in the past. Identification by measurement also requires relatively complete specimens, and can only be applied to a relatively small proportion of fragments.

Assumption 2 therefore requires some qualifications. We do not systematically test the quality of our identifications using "blind" tests. The only criterion for the validity of identifications is the reputation and experience of the analyst. Consequently we have no idea of the accuracy of our methods. All identification methods have potential flaws, and while most zooarchaeologists would probably agree that most identifications are probably accurate, they have no empirical or theoretical basis for this claim.

\section{Taxonomic Diversity}

A further problem in identification concerns the very uneven diversity of species in separate lineages. In part this is due to differences in the importance of "lumping" and "splitting" for taxonomists studying different vertebrate classes. In part it also reflects the evolutionary history and adaptive radiation of certain vertebrate lineages. The problem for the zooarchaeologist is that some types of animals are easily identified to the species level, because nothing else anywhere in the world resembles their skeletons, while other species are virtually indistinguishable on osteological evidence. For North America we could cite the familiar beaver (Castor canadensis) as an example. Many of the bones of this species are so distinctive that a high frequency of specimens can be identified confidently to the species level. This situation can be contrasted with North American microtine rodents, whose post-cranial skeletons are so similar that, with the exception of the very large muskrat, individual bones can only be identified to the family or sub-family level. Identification of species for microtines can only be undertaken through analysis of teeth, and even then some species are not separated easily. Clearly, we can expect a higher frequency of bones of some species to be identified to the species level than others. If a major goal of zooarchaeological analysis is calculation of relative frequency of species, some species will be more abundant simply because their skeletons are more easily identified.

There appears to be no solution to this problem at present. It is not possible to calculate species abundance by selecting only elements (such as crania and mandibles) which are commonly identifiable to species in most cases, because cultural factors (e.g., butchery methods or differential transportation of elements) and natural factors (e.g., many taphonomic processes) may differentially affect the presence of these elements on a site. Calculation of minimum numbers of individuals (MNI) is not a solution either. Grayson (1979) has shown that MNI is not independent of the number of indentified specimens (NISP); consequently, MNI does not provide an estimate of relative abundance independent of the number of identified elements. Species with large numbers of identifiable post-cranial elements will provide higher MNI values than species in which only mandible and cranium can be identified to species.

\section{Identification by Association}

Most of the discussion so far concerns the problems of actually identifying individual specimens. In spite of the various problems discussed, most zooarchaeologists would probably agree that an unknown but high percentage of specimens identified by reasonably competent and experienced zooarchaeologists familiar with the fauna of a particular region are correct. 
Table 1. Element frequencies and percentages for fauna on two hypothetical sites.

\begin{tabular}{lllll}
\hline Site & U1 & U2 & S & L \\
\hline$X_{\text {actual }}$ & 100 & - & 100 & 100 \\
$\%$ & 33 & - & 33 & 33 \\
& & & & \\
$Y_{\text {actual }}$ & 50 & 50 & 100 & 100 \\
$\%$ & 17 & 17 & 33 & 33 \\
$X_{\text {reported }}$ & 100 & - & 100 & 100 \\
$\%$ & 33 & - & 33 & 33 \\
$Y_{\text {reported }}$ & 20 & 20 & 100 & 100 \\
$\%$ & 8 & 8 & 42 & 42 \\
\hline
\end{tabular}

However, further problems are encountered when zooarchaeologists begin to make assumptions about the specific identity of taxa identified to a more general level than that of the species.

We can begin this discussion by considering the relatively rare circumstance of identifying bones from a site where a single species is encountered. Although zooarchaeologists working in the North American plains are familiar with this in the case of bison kill sites, on a global scale this is a somewhat unusual occurrence. If one examines faunal reports from bison kill sites, one finds that species identifications are made of some elements which would normally be relegated to a much more general taxonomic category. In fact, in most cases, virtually every bone fragment which can be identified to element is assumed to be from a bison. In such a case one can argue that this practice is reasonable, and that if all the femora, humeri, crania, etc. are from Bison bison, then less diagnostic elements such as rib shaft fragments or vertebral zygapophyses are probably from the same species. However, the identification of these fragments to the species level depends entirely upon their association with the specimens which possess characteristics which allow identification of species. If such fragments were encountered in sites in which other large ungulates were identified, they would almost certainly be relegated to the category "large ungulate", or some such similar designation.

The practice of "identification by association" is not only, as will show, potentially misleading; it is also unnecessary. With the possible exception of articulated specimens (a special instance discussed later), every bone fragment should be identified on its own merits. Thus, a summary of fauna from a monospecific assemblage should include fragments identified to the species, genus and family level, as well as some fragments identified to the archaeologically created categories of the "large ungulate" type. Once the identifications have been made and tabulated, the zooarchaeologist may wish to argue that, for the purposes of certain analyses (perhaps element frequency), the assumption will be made that all fragments identified to more general levels are in fact from a single species. In other words, the previously hidden assumption is made clear, the reasoning behind the assumption is made plain, and one can then proceed with the analysis.

Such a procedure is recommended here not simply because it places identification on a more formal footing. It has practical implications for inter-site comparisons. To illustrate this, one may imagine two single-component archaeological sites, $\mathrm{X}$ and $\mathrm{Y}$, located in the same general region but in different habitats. Site $\mathrm{X}$ contains three species: a large ungulate (U1), a small ungulate (S), and a lagomorph (L). Site Y contains four species: two large ungulates (U1 and U2), and the same small ungulate and lagomorph found in site $\mathrm{X}$. The analyst of the site $\mathrm{X}$ fauna identifies all large ungulate bones as $\mathrm{U} 1$, all small ungulate bones as $\mathrm{S}$ and all lagomorph bones as L, using the type of "identification by association" principle discussed above. The analyst of the site $\mathrm{Y}$ fauna identifies some large ungulates as $\mathrm{U} 1$ and some as U2, but many fragments are not diagnostic of either species even though they are recognizable as large ungulates. These cannot, of course, be identified to species, although they could, as discussed later, be included in a general "large ungulate" category. Like the analyst of site $\mathrm{X}$, the site $\mathrm{Y}$ analyst also uses "identification by association" whenever possible, and therefore identifies all small ungulate and lagomorph bones on site $\mathrm{Y}$ as $\mathrm{S}$ and $\mathrm{L}$ respectively. We can therefore envisage two assemblages for each site. The first (the actual assemblage) represents the real numbers of fragments of each species which were in fact present at both sites. The second (the reported assemblage) is composed of specimens identified by the analysts (Table 1).

As the example shows, differences in identification methods may lead to different relative frequencies of different species. For example, the ratio of $\mathrm{L}$ to $\mathrm{U} 1$ changes from 2:1 in the actual site $\mathrm{Y}$ assemblages to 5:1 in the reported assemblages. Similarly the ratio of $\mathrm{L}$ to all ungulates (U1+U2) changes from 1:1 in site $\mathrm{X}$ to 5:2 in the reported assemblages from site $\mathrm{Y}$, even though 
the actual ratio remains constant from one site to the next.

Cases such as this will not necessarily arise provided that zooarchaeologists are aware of such problems in the data. However, unless the analyst of site X clearly differentiates between specimens which can be identified positively as species U1 and those which can only be identified on their own merits as large ungulates, the data produced by the analysis will be of limited value in any comparative studies, because it will not be possible to sort out which bones are really identifiable to the species level and which are assumed to belong to that species.

One could argue that such a problem would not arise if the analyst of site $\mathrm{Y}$ reported values for an extra category-"large ungulate." Indeed, this is a fairly common procedure in zooarchaeology. While this would solve the problem of looking at ungulate to lagomorph ratios, it still creates problems. For example, the importance of $\mathrm{U} 1$ in the site $\mathrm{Y}$ assemblage still cannot be compared with $\mathrm{U} 1$ values from site $\mathrm{X}$ because criteria used to identify the bones differed from one assemblage to the other. If, on the other hand, the site X analyst had used the "large ungulate" taxon for specimens which could not be identified positively as species $\mathrm{U} 1$, the assemblages would be comparable.

One other possible solution would be to calculate the ratio of $\mathrm{U} 1$ to $\mathrm{U} 2$ in the site $\mathrm{Y}$ assemblage, and then make the assumption that this same ratio applies to the "large ungulate" category. The "large ungulates" could then be assigned proportionately to species $\mathrm{U} 1$ and $\mathrm{U} 2$, and comparisons could be made with site X. Again, there are serious problems with this method. For example, if butchery practices differed between the two ungulate species, then more "large ungulate" fragments would derive from the species which had undergone more frequent bone breakage and comminution. The situation could be further confused if we added more sites to the example with new species of small ungulates and lagomorphs at some of the sites.

There are other problems with "identification by association." The practice almost certainly encourages complacency in identification procedures. If one begins with the assumption that all bones found in a supposedly monospecific assemblage are indeed from one species, then the likelihood of identifying the rare bone of another species of similar size is considerably diminished.

The practice of "identification by association" is of little value to zooarchaeology. Apart from being dishonest, such identifications can lead to either confusion or unwarranted conclusions. The practice should be discontinued. Zooarchaeologists should identify to a particular taxon only those bones which can unquestionably be assigned to it.

\section{A Set of Procedures for Zooarchaeological Identification}

Identification of specimens by zooarchaeologists is an attempt to place them into taxonomic and anatomical categories used in zoology. In view of the general robusticity of the system of binomial nomenclature, and (with the possible exception of fishes) the system for naming individual bones, this method of classification would seem to be the most appropriate for the initial stages of any zooarchaeological analysis in which knowledge about species representation is important. Even if one does not wish to use the binomial system and standard anatomical terms, most other imaginable classifications require prior knowledge of the taxon and element. Consequently standard zoological descriptors will continue to be important in zooarchaeological classification.

It is important for zooarchaeologists to realise that the evidence used by zoologists to establish their classificatory systems include a wide range of data which can never be observed in the archaeological record (Ross 1974). There is no expectation that all, or any, bones or bone fragments will be sufficiently distinctive to identify unequivocally the species defined by consideration of whole specimens. The classification that zooarchaeologists use was developed to meet the needs of zoologists who almost always have many complete specimens of the animals they are attempting to classify. It is inevitable that many zooarchaeological specimens will be recorded as "unidentifiable".

If most zooarchaeologists accept the use of zoological terms to identify bone fragments, one might expect unanimity on standardised methods for data reporting. However, it is unrealistic to propose this. Individual zooarchaeologists have different confidence levels (with a tendency for the more experienced to be less willing to differentiate between closely related species). Since comparative collections differ in quality, one's ability to identify bones is partly a function of where one works. Furthermore, different research goals may require different approaches towards identification. For example, if research is primarily oriented towards analysis of subsistence, it might well be a waste of time tracking down the occasional passerine bone in an assemblage dominated by large mammals. Alternatively, palaeoenvironmental studies 
require species identifications, and bone fragments which cannot be identified to that level can often be ignored, even though in other contexts they might provide information about element frequency or butchery. However, although we cannot expect complete standardisation of data reporting, it is nonetheless necessary to inform other archaeologists of how one has implemented the system of identification. In order to do this, one has to follow certain procedures, and these are outlined below.

Prior to beginning an analysis one should develop a set of rules about how identifications are to be made. I suspect that very few zooarchaeologists do this, although many assume that they have done so. In most cases, one has a fairly good idea of the type of fauna which will be recovered from a site, and can predict fairly well what sorts of decisions will be required during the course of the analysis.

The first rule of virtually any analysis must be that each fragment will be identified on its own merits, so that "identification by association" does not occur. However, one may decide to make exceptions to this rule (although I personally do not). For example, a complete articulated skeleton might contain some bones which are identifiable to species, while others are only identifiable to genus if found as individual specimens. In such a case, one might decide to allow the identification to species of all bones which are clearly articulated. Similar decisions must be made in the case of bone fragments which can be glued together. If one finds twenty fragments of a moose tibia which can be reconstructed, should it be identified as a single fragment of moose? Should each individually identifiable fragment be counted? Should each fragment be counted as a separate identifiable piece? One can make arguments for all procedures, but whichever is to be followed must be established prior to the beginning of the analysis, and should also be reported (briefly) in the faunal report.

One must also make decisions about how one will make taxonomic distinctions. As noted earlier, assumptions are always made about what species are represented in the fauna. If one begins with no assumptions, then identification is virtually impossible, because every fragment will have to be checked against far more species than is realistic. For example, on Canadian high arctic sites dating to the last 5000 years, the only Canidae likely to occur are Canis lupus, C. familiaris, Alopex lagopus and Vulpes vulpes. For most analysts these form the universe from which any specimens identified as Canidae must derive. Such North American species as Canis latrans, Vulpes velox or
Urocyon cinereoargenteus will be excluded from consideration by most analysts prior to attempting to identify canid bones. Decisions not to include certain species as possible sources of fauna result in a greater proportion of specific identifications. For example, using the Arctic example cited above, a canid femur which was demonstrably larger than a big fox but much smaller than a small wolf would have to be identified as a dog, Canis familiaris. However, if one was to include $C$. latrans in the list of "possible" species for the area, then the specimen would probably be identified as "dog/coyote sized canid".

In addition to deciding what species might be present in the area, analysts must also decide what elements of the skeleton can provide specific identifications. This varies from one taxonomic group to another. For example, identification of the various species of Canis must be undertaken on fairly complete mandibles or crania; distinctions between mule deer and white-tailed deer can be made only on the antlers. On the other hand, many bones of Castor canadensis can be identified to species because there are no closely related species in the region being studied. If one is willing to produce a list of species which are likely to occur in the site (which I have argued above is essential), then one should be able to predict in advance which species are likely to be difficult to separate. This will allow one to decide prior to the analysis which elements exhibit so much overlap in morphology and size that distinctions between species cannot be made. Once such decisions have been made, they should be adhered to, and should be reported in the published analysis.

Finally, it is very important that zooarchaeologists attempt whenever possible to report identifications in more detail than is usually done, so that the nature of identification methods can be understood by other archaeologists. As noted above, this should include brief notes about what taxa were considered separable, and what elements were used to separate taxa. Ideally, descriptive zooarchaeological reports which provide the basic information about a site's fauna should also include tables in which numbers of elements (or parts of elements, or butchering units, etc.) are recorded for each taxa. This not only allows other analysts to manipulate data on element frequency, it also provides a very good guide to the identification procedures utilised. For example, if a zooarchaeologist practices "identification by association," these tables will show elements such as ribs identified to fairly specific levels; on the other hand, tables produced by a zooarchaeologist who does not use the method will 
show ribs and other less diagnostic elements relegated to a more general category. Admittedly, such tables take up space. This problem can be solved by carefully constructed tables and a lot of fine print. It can also be solved by the somewhat controversial use of microfiche appendices or even floppy discs. The introduction of many tables of data is not generally approved by editors and publishers, but without them much of the information recorded by zooarchaeologists is lost. Such data are often vital to future researchers, and zooarchaeologists should promote their use.

\section{Conclusion}

The classification of specimens by element and taxon is a preliminary step of most zooarchaeological analyses. Zooarchaeologists generally use classificatory systems borrowed from zoology. It has been shown that the assumptions made by zooarchaeologists when using these systems, especially binomial nomenclature, are partly invalid. Furthermore, the procedures for actually identifying specimens are rarely made explicit, nor are most zooarchaeological identifications susceptible to testing or critical evaluation. We can place no confidence limits on identifications.

While it is desirable to begin testing our abilities to provide correct identifications, using carefully constructed blind tests to assess the reliability of the methods, we can make zooarchaeological data more trustworthy by following some simple procedures. We must make explicit which species have been considered as the "universe" from which identifications have been made. We must outline the way in which identifications were made, including details of comparative collections, keys, guides, and measurement systems used. We should avoid "identification by association". Data reporting should include more than a list of taxa accompanied by NISP and MNI values. Publication of data should, at the very least, include lists of elements identified to various taxa, preferably organised by provenance.

The arguments for these recommendations are unambiguous and easily defended. Zooarchaeological analysis does not stop at the site level. Any attempt to work with data compiled by other researchers requires that one assess whether data sets are comparable, and this means that details of identification procedures and results must be made explicit. If zooarchaeology has any claims to be scientifically based we must adopt procedures which make the methodology of data production clear to other researchers. Only then can past research contribute to future syntheses.

\section{Acknowledgements}

I am very grateful to Jack Nance who read an earlier draft of this paper and helped to clarify the distinctions between typology and identification, as well as making many other useful comments.

\section{References Cited}

Behrensmeyer, A. K., K. D. Gordon, and G. T. Yanagi. 1987. Trampling as a Cause of Bone Surface Damage and Pseudo-cutmarks. Nature 19:768-71.

Binford, L. R. 1981. Bones. Ancient Men and Modern Myths. Academic Press, New York.

Brown, C. L. and C. E. Gustafson. 1979. A Key to Postcranial Skeletal Remains of Cattle/Bison, Elk and Horse. Washington State University Laboratory of Anthropology Reports of Investigations 57.

Brumley, J. H. 1973. Quantitative Methods in the Analysis of Butchered Faunal Remains: a Suggested Approach. Archaeology in Montana 14(1):1-40.

Clason, A. T. 1972. Some Remarks on the Use and Presentation of Archaeological Data. Helinium 12(2):139-53.

Davis, S. J. M. 1987. The Archaeology of Animals. Batsford, London.

Driver, J. C. 1983. Minimum Standards for Reporting of Animal Bones in Salvage Archaeology: Southern Alberta as a Case Study. In Directions in Archaeology: a Question of Goals, edited by P. D. Francis and E. C. Poplin, pp. 199-209. University of Calgary Archaeological Association, Calgary.

Driver, J. C. 1987. Review of Mammalian Osteology (Gilbert) and Avian Osteology (Gilbert, Martin and Savage). Zooarchaeological Research News 6(1).

Gilbert, B. M. 1980. Mammalian Osteology. Missouri Archaeological Society, Columbia.

Gilbert, B. M., L. D. Martin, and H. Savage. 1985. Avian Osteology. Missouri Archaeological Society, Columbia.

Grayson, D. K. 1979. On the Quantification of Vertebrate Archaeofaunas. In Advances in Archaeological Method and Theory 2, edited by M. B. Schiffer, pp. 199237. Academic Press, New York.

Grigson, C. 1978. Towards a Blueprint for Animal Bone Reports in Archaeology. In Research Problems in Zooarchaeology, edited by D. R. Brothwell, K. D. Thomas, and J. Clutton-Brock, pp. 121-128. Institute of Archaeology Occasional Papers 3. 
Hayden, B. 1984. Are Emic Types Relevant to Archaeology? Ethnohistory 31(2):79-92.

Hill, J. and R. Evans. 1972. A Model for Classification and Typology. In Models in Archaeology, edited by D. L. Clarke, pp. 231-73. Methuen, London.

Jeffrey, C. 1977. Biological Nomenclature. Crane Russak, New York.

Johnson, E. 1985. Current Developments in Bone Technology. In Advances in Archaeological Method and Theory 8, edited by M. B. Schiffer, pp. 157-235. Academic Press, New York.

Krieger, A. D. 1944. The Typological Concept. American Antiquity 9: 271-88.

Lawrence, B. 1951. Post-cranial Skeletal Characters of Deer, Pronghorn and Sheep-goat, with Notes on Bos and Bison. Papers of the Peabody Museum of Archaeology and Ethnology 35(3).

Morey, D. F. 1986. Studies on Amerindian dogs: Taxonomic Analysis of Canid Crania from the Northern Plains. Journal of Archaeological Science 13:119145.

Morlan, R. E. 1986. Pleistocene Archaeology in Old Crow Basin: a Critical Reappraisal. In New Evidence for the Pleistocene Peopling of the Americas, edited by A. L. Bryan, pp. 27-48. University of Maine Center for the Study of Early Man, Orono.

Olsen, S. J. 1960. Post-cranial Skeletal Characters of Bison and Bos. Papers of the Peabody Museum of Archaeology and Ethnology 35(4).

Olsen, S. J. 1964. Mammalian Remains from Archaeological Sites, Part I, Southeastern and Southwestern United States. Papers of the Peabody Museum of Archaeology and Ethnology 56(1).

Olsen, S. J. 1968. Fish, Amphibian and Reptile Remains from Archaeological Sites, Part I, Southeastern and Southwestern United States. Papers of the Peabody Museum of Archaeology and Ethnology 56(2).

Pankhurst, R. J. 1978. Biological Identification: the Principles and Practice of Identification Methods in Biology. University Park Press, Baltimore.

Ross, H. H. 1974. Biological Systematics. Addison-Wesley, Reading.

Schmid, E. 1972. Atlas of Animal Bones. Elsevier, Amsterdam.
Shipman, P. 1981. Application of Scanning Electron Microscopy to Taphonomic Problems. Annals of the New York Academy of Sciences 376:357-86.

Smith, G. S. 1979. Mammalian Zooarchaeology, Alaska: A Manual for Identifying and Analyzing Mammal Bones from Archaeological Sites in Alaska. University of Alaska Anthropology and Historic Preservation Cooperative Park Studies Unit Occasional Paper 18.

Sneath, P. H. and R. R. Sokal. 1973. Numerical Taxonomy. W. H. Freeman, San Francisco.

Steward, J. H. 1954. Types of Types. American Anthropologist 56:54-7.

Sullivan, A. P. and K. C. Rozen. 1985. Debitage Analysis and Archaeological Interpretation. American Antiquity 50(4):755-79.

Van Couvering, J. A. 1980. Community Evolution in East Africa During the Late Cenozoic. In Fossils in the Making, edited by A. K. Behrensmeyer and A. P. Hill, pp. 272-298. University Press, Chicago.

Vaughan, P. C. 1985. Use-Wear Analysis of Flaked Stone Tools. University of Arizona Press, Tucson.

Watson, J. P. N. 1979. The Estimation of the Relative Frequencies of Mammalian Species: Khirokitia 1972. Journal of Archaeological Science 6:127-37.

Whallon, R. and J. A. Brown (eds.). 1982. Essays on Archaeological Typology. Center for American Archaeology Press, Evanston.

\section{Biosketch \\ Jon Driver is a Professor in the Department of Archaeology at Simon Fraser University (Canada), where he currently serves as Provost and Vice-President, Academic. He completed a B.A. at Cambridge and a Ph.D. at Calgary. He has undertaken zooarchaeological research in England, Canada and the USA. He is currently working on faunal assemblages from Colorado and New Mexico.}




\section{Comments on "Identification, Classification, \& Zooarchaeology"}

\author{
Kristine Bovy \\ Dept. Anthropology, University of Rhode Island \\ kbovy@mail.uri.edu
}

Re-reading Driver's paper was an eye opening experience. While I was pleased to find that I have internalized many of his suggestions, I was reminded of many others that I wish I had followed more closely. For the most part, his observations and recommendations are as true today as there were twenty years ago. For example, many beginning zooarchaeologists may be puzzled by Driver's remark that there is "a tendency for the more experienced [zooarchaeologist] to be less willing to differentiate between closely related species (65)." Wouldn't one get better at making more specific identifications with more practice? Driver's statement exactly captures how I feel when looking back at some of my early analyses-how could I identify that? The answer-I couldn't! It has taken fifteen years of analysis for me to more fully realize what can and cannot be identified.

Unfortunately, Driver's observation about the inadequacy of many comparative collections is also still salient today. For example, juvenile birds from zooarchaeological assemblages are often left unanalyzed due to the lack of sub-adult comparative specimens. Although immature birds can be difficult to identify, such analyses can reveal important biogeographic information about past breeding distributions and can have relevancy for the management of current bird species (e.g. Bovy 2011). In addition, Driver commented on the difficulty of distinguishing fragmented bird bones from small mammals. I have also observed cases in which immature bird bones were sorted with the mammal bones because of their spongy appearance. Some juvenile bird bones may never make it to the bird bone analyst, but are relegated to "unidentified" mammal.

There are at least two aspects of zooarchaeology that are different today than in 1992. First, Driver notes, "for most vertebrate zooarchaeologists this [taxonomic revision] is not a major problem, because revisions tend to be rare and minor (61)." However, extensive genetic studies in biology in the past twenty years have created significant changes in bird taxonomy. In the 2010 installment of the annual supplement to the Check-list of North American Birds (Chesser et al., 2010), the American Ornithologists'
Union re-arranged a number of taxa in response to recent genetic studies and created four new taxonomic orders: Phaethontiformes (Tropicbirds), Suliformes (Frigatebirds, Boobies, Cormorants, Darters, and Allies), Accipitriformes (Hawks, Kites, Eagles, and Allies), and Eurypygiformes (Sunbittern and Kagu); herons were also moved from Ciconiformes (now just Storks) to Pelecaniformes (Pelicans, Herons, Ibises, and Allies). Therefore, taxonomic identifications made just a few years ago, may now mean something quite different. For example, a specimen identified conservatively in the past as "Falconiformes" (formerly "Diurnal Birds of Prey") could now be assigned to either "Accipitriformes" or "Falconiformes" (Caracaras and Falcons). It is now essential that bird analysts keep on top of these yearly updates, and also be explicit about what version of the checklist and updates are being used in a given report.

Second, it has obviously become much easier to share raw data with other analysts via the internet, and some journals allow authors to include online appendices or supplements to articles. In addition, the archaeology program of the National Science Foundation requires those applying for a grant to submit a "data access plan" detailing how the primary data will be disseminated. As more analysts take advantage of new digital options, it will hopefully become more common to have access to original data and tables, rather than just the short summary tables allowed in many journal articles.

As I begin a new zooarchaeological analysis this fall and train students to help in the lab, I plan to review Driver's article again, and make sure the hidden assumptions of zooarchaeology are transparent to these budding zooarchaeologists as well. I may even post the following quote from Driver's article in the lab as a reminder to do good work: "Zooarchaeologists should identify to a particular taxon only those bones which can unquestionably be assigned to it (65)."

\section{References Cited}

Bovy, K. M. 2011. Archaeological Evidence for a Double-crested Cormorant (Phalacrocorax auritus) Colony in the Pacific Northwest, USA. Waterbirds 34(1):89-95.

Chesser, R. T., R. C. Banks, F. K. Barker, C. Cicero, J. L. Dunn, A. W. Kratter, I. J. Lovette, P. C. Rasmussen, J. V. Remsen, Jr., J. D. Rising, D. F. Stotz, and K. Winker 2010. Fiftieth Supplement to the American Ornithologists' Union Check-list of North American Birds. The Auk 127:726-744. 


\section{Comments on "Identification, Classification, \& Zooarchaeology"}

\author{
Virginia L. Butler \\ Dept. Anthropology, Portland State University \\ virginia@pdx.edu
}

I am pleased to see the republication of Jon Driver's 1992 paper. He makes many excellent points about zooarchaeological methods and reporting of faunal data, especially the need to be explicit about the basis of our taxonomic identifications, including assumptions we make about which taxa are in our geographic universe and other factors that help determine whether a species, genus, or family level assignment is appropriate. There are many reasons we should follow Driver's suggestions. Being explicit about the source of our identifications allows for others to evaluate claims, prerequisite to the scientific enterprise. We can also build on others' work, not having to re-invent the wheel in developing distinguishing criteria. Another reason is associated with data synthesis. Aggregating faunal data across multiple projects and analysts can be challenging, if not impossible when methods of analysis are vague or obscure. In addition, as we work to insinuate zooarchaeological research into more public domains such as wildlife and conservation policy, we will need to defend our identifications in those public domains including the courts. We want the products of our research to stand up to the closest scrutiny as we leave the "ivory tower" and the stakes increase. Driver's paper provides very useful guidance here.

I have two main points to make. First, I want to explore the use of "identification by association", which Driver suggests is of little value to zooarchaeology. As Driver explains, this practice begins with the taxonomic assignment of some specimens in a given site context, based on morphological or other criteria, and then "by association", assigning a larger set of specimens to that taxon simply because of context, not based on independent criteria. For example, if one was able to identify some number of a site's fish remains from the family Catostomidae (sucker) to the species Catostomus macrocheilus (largescale sucker), then by association, one could assign all the sucker remains to C. macrocheilus, not just the ones assigned based on morphology, given that this is the only species (of several others in the region) present. Driver suggests that faunal analysts should avoid this practice, arguing instead that each bone be examined and taxonomically identified on its own merit. I argue that the problem with "identification by association" is not the use of context to make a claim, but rather the lack of background information in a report that would explain the analytic decision used to make the taxonomic assignment. If one is explicit about analytic decisions and protocols used to assign specimens to various taxonomic levels and describes which specimens were assigned based on morphology and association, then other researchers can evaluate the knowledge claims and decide whether to accept them. The key piece here is being explicit, shining a light on the hidden assumptions.

Second, I want to propose a bit of activism in the zooarchaeology community, if we all agree with Driver and the underlying value of promoting rigorous approaches to faunal analysis and reporting of data. As with archaeology overall, in North America most funded faunal analysis and reporting takes place under the umbrella of heritage or cultural resources management. In the United States, state level offices (known variously as Office of Historic Preservation, State Historic Preservation Office, etc.) set guidelines for archaeological work and reporting. At least in Oregon and Washington, guidelines for zooarchaeological data reporting do not exist; I suspect many states and Canadian provinces lack state-level guidelines. I suggest that we come up with some general guidelines for faunal sampling, analysis and reporting and that we work with our state/provincial historic preservation officers to get them integrated into archaeology practice guidelines. Because of varying goals and research interests, we don't want to mandate that all faunal analyses conform in lock-step to the same procedures. On the other hand we might "raise our game" more broadly, encouraging greater rigor and explicitness regarding taxonomic identification (and other important aspects of analysis and reporting), if we work to develop guidelines/ policies that management agencies could use. Writing papers in peer-reviewed journals may not be sufficient to lead to the kinds of changes Driver and others of us want to see.

\section{Comments on "Identification, Classification, \& Zooarchaeology"}

\author{
Karen D. Lupo \\ Dept. Anthropology, Washington State University \\ klupo@wsu.edu
}

In the nearly two decades since Driver's (1992) publication appeared in Circaea, identification techniques for faunal remains from archaeological sites have greatly expanded and become far more 
sophisticated. The application of new techniques for analyzing ancient genomics (ancient DNA) are becoming more widespread and allow for the precise identification of different species (e.g., Barnes et al. 2000; Horsburgh 2008; Yang et al. 2005). In many cases, these same identifications could not have been justified solely on the basis of bone characteristics or morphometrics. Other kinds of techniques applied to different archaeological data, such as lipid residue analysis of tools and the identification of isotopic signatures, are increasingly providing additional details on the prehistoric use of animals. Novel identification techniques based on bone histology are expanding analysts ability to identify the largely fragmented bones recovered in zooarchaeological contexts (Cuijpers 2006). Even as these new techniques become more widespread, however, most analyses of zooarchaeological assemblages still rely largely on more conventional sources of information such as comparative collections, published keys, the experience of the analyst and contextual information. But even some of these conventional sources are enhanced by the large number of manuals, keys and articles on bone identification focusing on a single taxon or comparing a few closely related species that have been and continue to be published since the early 1990's (e.g., Crockford 2009; Semkin and Wallace 2002). On-going assessments and refinements of standard identification criteria based on skeletal elements are distinguishing useful traditional criteria from those that are ambiguous (see Zeder and Lapham 2010 for a recent example). The perennial problem of a lack of access to adequate comparative collections is improved by digital, 3-D images that are becoming increasing available on the internet. Although most current collections of digital images are a long way from capturing the range of ontogenetic, sexual, and geographic variability displayed by most animal populations, this deficit will undoubtedly be closed in the future. Thus, faunal analysts now have many more identification tools in their arsenal than they did 30 years ago, and the potential for identifying large numbers of highly fragmented prehistoric faunal specimens has never been greater.

Despite the advantages that new developments afford, some of the problems identified by Driver persist but are now manifested in different ways. Elements of Driver's two fundamental and inter-related suggestions concerning standardization and transparency in taxonomic identifications still resonate today. To a certain extent, the realization of these objectives, is uneven in the field zooarchaeology and varies, in part, as a function of the analytical technique used by the researcher. For example, transparency in methodology and protocols are compulsory in most ancient genomic analyses. Replication of results and duplicate testing in different laboratories are also part of the standard protocol. With the exception of rare or potentially controversial specimens, most conventional zooarchaeological analyses based on bone morphology and standard landmarks are often less clear about methodology. Replication of results is not part of the standard protocol. While transparency in identification procedures in more conventional zooarchaeological analyses is on the rise, especially in archaeological reports, Driver's vision of clear procedural outlines for taxonomic identification remains unfulfilled. The sequence he envisioned involved analysts making a series of decision rules guiding how each fragment was to be identified before and during analysis. In practice, most analysts probably have developed a series of identification decision rules, but inclusion of these rules in publications is often overlooked. This is particularly problematic in analyses where bone fragments are assigned to animal size-class. Because most analyses still rely largely on conventional identification sources, the use and clear reporting of procedures is critical and should be expanded beyond the rare or unique finds. If zooarchaeology is to prevail as an integrated sub-field in archaeology, then analysts need to strive to develop and apply common standards to all forms of identification.

\section{References Cited}

Barnes, I., J.P.W. Young, and K. Dobney. 2000. DNABased Identification of Goose Species from Two Archaeological Sites in Lincolnshire. Journal of Archaeological Science 27:91-100.

Crockford, S. J. 2009. A Practical Guide to in situ Dog Remains for the Field Archaeologist. Pacific Identifications, Inc.

Cuijpers, A. G. F. M. 2006. Histological Identification of Bone Fragments in Archaeology: Telling Humans Apart from Horses and Cattle. International Journal of Osteoarchaoelogy 16:465-480.

Horsburgh, K. A. 2008. Wild or Domesticated? An Ancient DNA Approach to Canid Species Identification in South Africa's Western Cape Province. Journal of Archaeological Science 35:1474-1480.

Semken, H. A. and S. C. Wallace. 2002. Key to Arvicoline ("Microtine" rodents) and Arvicoline-like Lower First Molars Recovered from Late Wisonsinan and Holocene Archaeological and Palaeontological 
Sites in Eastern North America. Journal of Archaeological Science 29:23-31.

Yang, D. Y., J. R. Woiderski, and J. Driver. 2005. DNA Analysis of Archaeological Rabbit Remains in the American Southwest. Journal of Archaeological Science 32:567-578.

Zeder, M. and H. Lapham. 2010. Assessing the Reliability of Criteria Used to Identify Postcranial Bones in Sheep, Ovis, and Goats, Capra. Journal of Archaeological Science 37:2887-2905.

\section{Comments on "Identification, Classification, \& Zooarchaeology"}

\author{
R. Lee Lyman \\ Dept. Anthropology, University of Missouri \\ lymanr@missouri.edu
}

Zooarchaeologists often do not report the anatomical criteria they have used to identify individual bones or teeth or shells as representing particular species. Although perhaps understandable if one is of the opinion that discussions of taxonomically diagnostic morphometric features are simply "descriptive" and thus unworthy of page space in our professional journals, such an opinion is naive. Taxonomic identification of animal remains recovered from archaeological excavations is the most fundamental and significant step of virtually any analysis of ancient faunal remains, regardless of the research question being asked or the hypothesis being tested. Taxonomic identification is, however, superficially simple. In one of the best descriptions of the protocol I have found, paleontologist George Gaylord Simpson (1942:144) noted that one first assumes "that the bones of different [taxa] have characteristic forms, more or less constant for any one [taxon]" (Simpson 1942:144). Under this assumption, the zooarchaeologist places two homologous bones (say, two femora) next to one another "and looks" (Simpson 1942:145), concluding that if the two bones look alike they are from the same taxon, but if they look different they are from different taxa. The "characteristic forms" or features of a bone or tooth or shell of a particular taxon constitute the necessary and sufficient conditions for identifying an archaeological specimen as a member of that taxon.

Perhaps because it is thought to be simple, many feel they can identify bones with minimal training and perhaps a skeletal guidebook such as Gilbert (1990). Unfortunately, this is not at all true. For example, at a minimum, such guidebooks not only seldom include more than one view of each skeletal element, they often present that view at a non-life-size scale, taxonomically diagnostic features are not indicated, and individual (intrataxonomic) variation due to age and sex and population differences is not indicated. To these facts can be added two more. First, many archaeological specimens are incomplete anatomical units such as a distal femur or a fragment of a proximal radius, and therefore fewer of the taxonomically diagnostic features are present. Second, many species have closely related congeners (other species of the same genus) that display similar skeletal features. Simply put, taxonomic identification is not simple.

Twenty years ago, Jon Driver (1992) wrote his thoughtful paper on the weaknesses of what he took to be the general protocol of taxonomic identification of archaeological faunal remains. Subsequent studies of taxonomic identification procedures, while few in number (e.g., Bochenski 2008; Gobalet 2001; Lyman 2002), have reinforced much of what Driver said originally. Yet the identification protocol deserves further study. Driver's paper is a great place to start and it is thus very appropriate that it is reprinted in a venue that will see it and that the fundamental topic receive more attention.

Driver argues that each specimen (individual bone or tooth or shell or fragment thereof) should be identified "on its own merits" by which he means its intrinsic anatomical and morphometric attributes. I agree. Driver also argues for standardization of identification procedures and rules. I agree to the extent that we all use comparative collections of actual skeletons rather than some use guidebooks, some use comparative skeletons, and some use seat-of-the-pants. $\mathrm{He}$ advocates standardization of identification procedures and rules because at present the only criterion by which to judge the validity of any particular identification is the "reputation and experience of the analyst." This qualified authority notion has some validity (e.g., Woodward and Goodstein 1996), and while perhaps necessary to evaluate an identification, it is not sufficient. Driver's solution to this dilemma is to recommend that an identification be reported in sufficient detail that it can be understood by the reader why a particular specimen has been identified as representing species A rather than species B or species C. To me, this only begs the question of what "sufficient detail" means. Further, it ignores a historically well-established protocol.

In the early history of zooarchaeology, it was paleontologists and zoologists who identified archaeologically recovered faunal remains to taxon (e.g., 
Gilmore 1949; Merriam 1928; White 1953). Paleontology has had, virtually since it became a distinct science (roughly 200 years ago at the hands of Georges Cuvier [Rudwick 1976]), a standard protocol for reporting identifications. In a typical paleontological study there is a section entitled "Descriptive Paleontology" or "Systematic Paleontology." There, all identified specimens are listed under each taxon, each specimen is described, and the anatomical and morphometric criteria used to make the identification are described verbally and exemplary specimens are illustrated. The taxonomically diagnostic anatomical features used to identify specimens as representing a particular species become well known among those studying particular taxa and undergo blind tests every time a paleontological report undergoes peer review and is published. Someone is sure to point out when allegedly diagnostic anatomical features are not taxonomically diagnostic. A novice zooarchaeologist (and even many experienced ones) can do little better than to read paleontology when it comes to learning the protocol of taxonomic identification (e.g., Barnosky 2004; Guilday et al. 1964, 1977, 1978). That protocol addresses every problem Driver identifies.

\section{References Cited}

Barnosky, A. D. (ed.) 2004. Biodiversity Response to Climate Change in the Middle Pleistocene: The Porcupine Cave Fauna from Colorado. University of California Press, Berkeley.

Bochenski, Z. M. 2008. Identification of Skeletal Remains of Closely Related Species: The Pitfalls and Solutions. Journal of Archaeological Science 35:1247-1250.

Driver, J. C. 1992. Identification, Classification and Zooarchaeology. Circaea 9:35-47.

Gilbert, B. M. 1990. Mammalian Osteology. Missouri Archaeological Society, Missouri State University, Springfield.

Gilmore, R. M. 1949. The Identification and Value of Mammal Bones from Archeological Excavations. Journal of Mammalogy 30:163-169.

Gobalet, K. W. 2001. A Critique of Faunal Analysis: Inconsistency among Experts in Blind Tests. Journal of Archaeological Science 28:377-386.

Guilday, J. E., P. S. Martin, and A. D. McCrady. 1964. New Paris No. 4: A Pleistocene Cave Deposit in Bedford County, Pennsylvania. Bulletin of the National Speleological Society 26:121-194.

Guilday, J. E., P. W. Parmalee, and H. W. Hamilton. 1977. The Clark's Cave Bone Deposit and the Late Pleistocene
Paleoecology of the Central Appalachian Mountains of Virginia. Bulletin of the Carnegie Museum of Natural History

No. 2.

Guilday, J. E., H. W. Hamilton, E. Anderson, and P. W. Parmalee. 1978. The Baker Bluff Cave Deposit, Tennessee, and the Late Pleistocene Faunal Gradient. Bulletin of the Carnegie Museum of Natural History No. 11.

Lyman, R. L. 2002. Taxonomic Identification of Zooarchaeological Remains. The Review of Archaeology 23(2):13-20.

Merriam, C. H. 1928. Why Not More Care in Identifying Animal Remains? American Anthropologist 30:731-732.

Rudwick, M. J. S. 1976. The Meaning of Fossils: Episodes in the History of Palaeontology, revised edition. Neale Watson Academic Publications, New York.

Simpson, G. G. 1942. The Beginnings of Vertebrate Paleontology in North America. Proceedings of the American Philosophical Society 86:130-188.

White, T. E. 1953. Studying Osteological Material. Plains Archaeological Conference News Letter 6:58-66.

Woodward, J. and D. Goodstein. 1996. Conduct, Misconduct and the Structure of Science. American Scientist 84:479-490.

\section{Comments on "Identification, Classification, \& Zooarchaeology"}

\section{Clara Otaola \\ Museo de Historia Natural de San Rafael-CONICET claraotaola@arqueologiamendoza.org}

The republication of Driver's paper is important and is of interest in Argentina where the earliest papers about methods in faunal analysis either emphasized taxonomic identification or quantification of bone specimens. Emphasis varies according to where archaeology programs are housed. Those in programs within departments housed in the natural sciences, focus on the importance of zoological taxonomy during the identification process (Salemme et al. 1991; Tonni 1984). On the other hand, those trained in departments housed in the social sciences, despite treating faunal identification as a fundamental aspect of zooarchaeological research, emphasize the problems of quantification, the derivation of analytical units, and the development of models of past human behaviour related to subsistence (Mengoni Goñalons 1981, 1988). Both perspectives are important for the development 
of zooarchaeology in Argentina. Howev-er, a common standard for faunal identification as described by Driver has not been adopted.

Zooarchaeological research has increased during the last thirty years in Argentina (Mengoni Goñalons 2004, 2010), but much remains to be accomplished concerning standardization in faunal analysis. Driver's paper is rarely cited by Argentine zooarchaeologists, though there are exceptions. A lack of attention to his paper reflects that many academic journals were difficult to access for much of the 1980s, 1990s, and early 2000s. The republication of this article in an open-access format provides the opportunity for Argentine zooarchaeologists to revisit the topic of standardization.

I would like to highlight one of Driver's ideas that is particularly important for the Argentine zooarchaeologist, the statement that zooarchaeological analysis does not stop at the site level. For decades the majority of the papers in zooarchaeology in Argentina were akin to faunal reports that relied heavily on faunal lists. Regional approaches comparing faunas from multiple sites analyzed by diverse research teams are becoming more common today (Barberena et al. 2009; Martinez and Gutiérrez 2004; Otaola 2010; Santiago and Vázquez 2011). Also, there has been an increase in collections-based research focusing on new questions, using new methods, especially for doctoral dissertation research. Such use of previously excavated and often previously analysed collections makes the establishment of a transparent faunal identification standard a necessity. Without such a foundation it is impossible to derive more sophisticated research orientations, such as taphonomic and theory-driven approaches.

Grayson (1984) warned over two decades ago that the zooarchaeological literature would grow to the point that it would become overwhelming. For the student, access to foundational literature can have an important impact on career development. Many papers and manuals discuss methods for analyzing faunas, but Driver's paper emphasizes the theory of identification, which is a fundamental aspect of zooarchaeology because all subsequent analyses depend on rigorous faunal identification.

\section{References Cited}

Barberena, R. A., F. Zangrando, A. F. Gil, G. A. Martínez, G. G. Politis, L. A. Borrero, and G. Neme. 2009. Guanaco (Lama guanicoe) Isotopic Ecology in Southern South America: Spatial and Temporal Tendencies, and Archaeological Implications. Journal of Archaeological Science 36:2666-2675.
Grayson, D. K. 1984. Quantitative Zooarchaeology.

Academic Press, Orlando, FL.

Martínez, G. and M. Gutiérrez.2004. Tendencias en la Explotación Humana de La Fauna Durante el Pleistoceno Final y Holoceno en la Región Pampeana (Argentina) In Zooarchaeology of South America, edited by G.L. Mengoni Goñalons, pp. 81-98. BAR International Series, 1928. Archaeopress, Oxford.

Mengoni Goñalons, G. L. 1981. Obtención de Información Cultural de Arqueofaunas. Técnicas de Estudio y Análisis de Material Arqueológico. Facultad de Filosofía y Letras, UBA, pp. 15-33, Buenos Aires.

Mengoni Goñalons, G. L. 1988. Análisis de Materiales Faunísticos de Sitios Arqueológicos. Xama 1:71-120.

Mengoni Goñalons, G. L. 2004. An Overview of South American Zooarchaeology. In Zooarchaeology of South America, edited by G. L. Mengoni Goñalons, pp. 1-9, BAR International Series 1298. Archaeopress, Oxford.

Mengoni Goñalons, G. L. 2010. Advances in Animal Bone Archaeology in Argentina: General Trends and Some Prospects for the Future. In Current Advances for the Latin-American Archaeozoology, edited by G. L. Mengoni Goñalons, J. Arroyo Cabrales, Ó. Polanco and F. J. Aguilar, pp. 17-26. Instituto Nacional de Antropología e Historia, México, D. F.

Otaola, C. 2010. Índices de Utilidad en Contextos Tafonómicos Variados. In Zooarqueología a Principios del Siglo XXI: Aportes Teóricos, Metodológicos y Casos de Estudio, edited by M. De Nigris, P. M. Fernández, M. Giardina, A. F. Gil, M. A. Gutiérrez, A. Izeta, G. Neme, and H. D. Yacobaccio, pp. 157-166. Ediciones del Espinillo, Buenos Aires.

Salemme, M., E. Tonni, and L. Miotti. 1991. The Determination of Mammal Bones in Zooarchaeological Research. In Recent Developments in Western Mediterranean Prehistory: Archaeological Techniques, Technology and Theory, Vol. I, edited by W. H. Waldren, J. A. Ensenyat, and R. C. Kennard, pp. 209-222. BAR International Series 573. Archaeopress, Oxford.

Santiago F. and M. Vázquez. 2011. Dietas Promediadas. Explorando el Registro Zooarqueológico Supraregional en Tierra del Fuego. Paper presented at the II Congreso Nacional de Zooarqueología Argentina, Universidad Nacional del Centro de la Provincia de Buenos Aires, Facultad de Ciencias Sociales, Olavarría.

Tonni, E. P. 1984. La Arqueología Biológica en la Argentina: El Estudio de los Vertebrados. ADEHA 6:1-11. 


\section{Twenty years after "Identification, Classification and Zooarchaeology"}

\author{
Jonathan C. Driver \\ Dept. Archaeology, Simon Fraser University \\ driver@sfu.ca
}

\begin{abstract}
In 1992 the author published "Identification, classification and zooarchaeology" in the journal Circaea. Although rarely cited, the article has appeared regularly on the reading lists of some courses in zooarchaeology, and has been reprinted in this issue of Journal of Ethnobiology, together with a number of comments. In this short paper the author provides some context for the original article, and reflects on how zooarchaeologists have approached some of the problems of specimen identification in the last twenty years.
\end{abstract}

Key Words: zooarchaeology, methods, identification

\section{Background}

"Identification, classification and zooarchaeology" (Driver 1992) was written originally as a contribution to a proposed Festschrift for Richard (Dick) Forbis, an archaeologist who specialized in the Northern Plains (Janes 1984), and who taught the graduate method and theory class in the Department of Archaeology, University of Calgary when I was a student. The intended volume was never completed, so I submitted the paper to Circaea, the journal of the Association for Environmental Archaeology, because I felt that it would appeal more to British zooarchaeologists than their North American counterparts. My undergraduate degree was from Cambridge, and I had spent a couple of years back in England working on Medieval faunas after completing my $\mathrm{PhD}$ in Calgary, so I was familiar with the British and, to a lesser extent, the European approaches to zooarchaeology.

"Identification, classification and zooarchaeology" (ICZ) reflects four influences. First, I had experience in research projects where comparison of zooarchaeological data from numerous excavations was yielding more robust information than single site reports. My $\mathrm{PhD}$ (completed in 1978) had taken a regional approach to a valley in the northern Rocky Mountains (Driver 1985a). In Britain I got to know members of the "Faunal Remains Unit", a government funded laboratory associated with Southampton University that took on a wide range of projects in southern England, and used regional data for interesting overviews (e.g., Maltby 1981). I had also completed a regional study of sites in eastern New Mexico (Driver 1985b). It had become apparent that reporting zooarchaeological data for a single excavation was only valuable if future researchers understood what criteria were used to identify animal remains, so that data from numerous sites could be combined for comparative or synthetic purposes.

Second, I had been strongly influenced by the work of Don Grayson on quantification. In 1982, I replaced Rick Casteel as the zooarchaeologist at Simon Fraser University, and his students convinced me that I should pay more attention to quantification methods. A close reading of Grayson's work, especially his first comprehensive analysis of the issues (Grayson 1979); showed me that failure to understand fundamental aspects of data generation would lead to unsupportable interpretations. The influential books on taphonomy that appeared in the early 1980's (e.g., Behrensmeyer and Hill 1980; Binford 1981; Brain 1981) contained numerous case studies of the dangers of making assumptions about the underlying natural and cultural processes that created faunal assemblages. However, what particularly struck me about Grayson's work was the potential for archaeologists themselves to structure assemblages in ways that would affect the interpretation of their data. Just as Grayson had investigated how choice of quantification methods affected assemblage composition and interpretation, I wanted to investigate how the identification of zooarchaeological specimens could do the same.

Third, having employed undergraduate and graduate research assistants, I had realized that in order to ensure comparability of results within my own projects, I would have to define protocols for recording specimens. This required standardized coding (so that we all spoke the same language), but I also wanted to ensure that we would be consistent in our identifications. I therefore began to develop rules for my students about what would and would not be considered "identifiable".

Finally, with the widespread availability of personal computers in the 1980's, it became more important to ensure that zooarchaeological specimens were recorded in a way that facilitated electronic sorting and manipulation of data. This also reinforced the need for clear protocols and coding systems for entry of descriptive data. By the mid-1980's I had given up recording basic information about specimens on paper, and this led to more careful thought before beginning an analysis about what ought to be recorded. For example, in ICZ I talked about the need to define a "universe" of taxa that would be considered as potentially identifiable in a particular region. That 
concept arose from having to make decisions about what taxa would receive codes when I was developing coding systems for use on personal computers.

ICZ focused on identification because I felt that this was fundamental to zooarchaeological analysis, and yet was rarely discussed as a methodological problem. There was a literature available on criteria for distinguishing different taxa, but very little had been written on the assumptions that underlay the actual decision to identify a particular specimen to a particular taxonomic category. I also wanted to get away from attempts that had been made by zooarchaeologists to standardize reporting methods (e.g., Grigson 1978) or create standard coding systems (e.g., Klein and CruzUribe 1984) because these approaches reduced zooarchaeological analysis to a method without a research problem.

\section{What Else Should have been Included}

In retrospect, there are two interrelated topics and an important earlier publication that I should have included in ICZ. First, as pointed out to me recently by Steve Wolverton, I should have investigated the literature on experimental protocols in science laboratories. My failure to do this is difficult to understand, because at the time the paper was written I was having regular conversations with physicist Erle Nelson, who did pioneering work on stable isotope analysis (e.g., Chisholm, Nelson and Schwarcz 1983 ) and AMS radiocarbon dating (e.g., Nelson et al. 1986), and was a colleague in the same department. A frequent topic of our discussions was the reliability and precision of results, particularly when AMS laboratories were being developed around the world. However, I didn't connect our discussions about reliability, accuracy and precision in science labs to my own concerns about identifying faunal specimens.

Second, I was already aware of the processes that vertebrate palaeontologists used to formally describe faunas, and of the fact that a group of zooarchaeologists trained at University of Wyoming had long used a descriptive approach derived from paleontology for reporting identifications (e.g., Walker and Frison 1980). I should have discussed the formality of that approach as a contrast to the more informal approach adopted by most zooarchaeologists.

I should also have been aware of Barbara Lawrence's paper on methodological problems raised during inter-site analysis, especially as the book in which it appeared was in the SFU library at the time. Lawrence argued that in order to undertake inter-site comparisons it was necessary to agree on the criteria to be used for identification, and to report them. Although she did not explore this topic in as much detail as ICZ, she was clearly aware of the fundamental issue: "the comparability of analyses can only be evaluated if the foundations on which these rest are fully described" (Lawrence 1973:399).

\section{Subsequent Developments}

ICZ seems to have had little impact on zooarchaeological practice and has been cited rarely, although it is now available online through the Association for Environmental Archaeology web site. A few zooarchaeologists have told me that they include the paper as required reading for undergraduate or graduate classes. My experience in compiling data from dozens of sites in British Columbia and from hundreds of sites in the American Southwest has shown that few zooarchaeologists discuss identification procedures in publications or in the grey literature, and I continue to believe that this is a failing of our research field almost 40 years after Lawrence first defined the problem.

There have been a number of developments since 1992 that should be noted. One of my former graduate students, Randall Preston, pointed out that one would have greater confidence in reported identifications if analysts carried out "blind" re-analysis of specimens. As far as I know, Randall was the first zooarchaeologist to deliberately undertake this process, and I have encouraged all of my students to follow his example and report the reliability of their own identifications, based on a protocol for re-analyzing a portion of the assemblage.

A more sophisticated experiment in assessing the accuracy of identifications was undertaken by Ken Gobalet (2001), who submitted the same collection of fish bones to different analysts, and reported the discrepancies between them. This paper was published in a journal that is widely read by zooarchaeologists, yet the paper is rarely cited, something that I find hard to understand. Zooarchaeologists claim the ability to identify complete and fragmentary specimens from the vertebrate skeleton. They provide no proof that they can do this either reliably or accurately, and when someone conducts an experiment that throws the most basic aspect of zooarchaeology into question, there is virtually no reaction. Gobalet's paper should have been a wake-up call to the discipline. At the very least it should have prompted further experiments to assess whether this problem is widespread, and whether it is more prevalent for certain kinds of fauna - maybe fish are more difficult to identify than mammals? 
Another important development that was just on the horizon in the early 1990's is the ability to present massive amounts of information electronically, and to provide remote access to the data. This means that zooarchaeologists can archive detailed discussions of identification methods online, and that they can store complete data sets in accessible formats. Of course, this makes the reliability and accuracy of the data even more important. One encouraging sign is that more people are posting photographs of "difficult" specimens online, and asking colleagues to assist in identification. Also encouraging is the willingness of many journals to electronically archive data and descriptions of experiments that support the conclusions of published papers. It is interesting to note that the Society for American Archaeology's January 2011 Archaeological Record contains a series of short articles about the potential for storing and sharing zooarchaeological information using digital formats.

However, the biggest change in identification methods since ICZ was published is the development of ancient DNA analysis (aDNA). This has revolutionized understanding of late Pleistocene and Holocene plants and animals, their genetic and ecological relationships, and their interaction with people. However, there has been surprisingly little use of aDNA as a method for independent confirmation of taxonomic identification based on more traditional zooarchaeological methods. There are some interesting examples that demonstrate the potential of aDNA as a check on the validity of identification methods. For example, while working on a large collection of rabbits from a site in the American Southwest, Yang et al. (2005) used aDNA to check the separation between Lepus and Sylvilagus on the basis of size. While the aDNA verified the legitimacy of element size as a distinguishing criterion (a not unexpected result), it also revealed the presence of a small Lepus species that was present regionally, but thought to be very unlikely to occur around the site that had been excavated. Another interesting example is Ann Horsburgh's analysis of Iron Age canids in South Africa. She reports that the context and abundance of canid remains had led archaeologists to assume that domestic dogs were present, but all of the specimens she tested were blackbacked jackals, a local wild canid (Horsburgh 2008).

Tarcan and I used aDNA on a small number of specimens to test our ability to separate species and genera of medium-sized artiodactyls from the historic contexts at Zuni Pueblo, New Mexico (Tarcan and Driver 2010). As analysis of aDNA samples becomes faster and cheaper, we should expect to see some systematic testing of identification of ancient faunal specimens that had been identified through more traditional zooarchaeological methods, such as morphology or biometrics. Such experiments would help delineate the kinds of specimens that we have the most difficulty in identifying accurately, and could provide zooarchaeologists with some best practices for various categories of taxa.

\section{Conclusion}

In the late 1980's a combination of factors, both practical and theoretical, led me to reflect on the process of making an identification during a zooarchaeological analysis. I believe that my 1992 paper in Circaea presented some troubling issues with the most fundamental aspect of zooarchaeology - attaching a taxonomic designation to a fragment of a skeleton. I do not think that we have resolved most of these issues. Our continued assumption that identification is an acquired skill that cannot be subjected to rigorous confirmation procedures makes zooarchaeology less credible, especially to scientists from other disciplines.

\section{Acknowledgements}

I thank Steve Wolverton for providing the opportunity to reprint my 1992 paper in Ethnobiology Letters, and for organizing the comments about the paper. I also thank Daniela Balanzetegui for her editorial assistance.

\section{References Cited}

Behrensmeyer, A. K. and A. P. Hill (eds.) 1980. Fossils in the Making, Vertebrate Taphonomy and Paleoecology. University of Chicago Press, Chicago

Binford, L. R. 1981. Bones. Ancient Men and Modern Myths. Academic Press, New York.

Brain, C. K. 1981. The Hunters or the Hunted? University of Chicago Press, Chicago.

Chisholm, B. S., D. E. Nelson, and H. P. Schwarcz. 1983. Marine and Terrestrial Protein in Prehistoric Biets on the British Columbia Coast. Current Anthropology 24:396-398.

Driver, J. C. 1985a. Prehistoric Hunting Strategies in the Crowsnest Pass, Alberta. Canadian Journal of Archaeology 9:109-129.

Driver, J. C. 1985b. Zooarchaeology of Six Prehistoric Sites in the Sierra Blanca Region, New Mexico. Museum of Anthropology University of Michigan Technical Report 17.

Driver, J. C. 1992. Identification, Classification and Zooarchaeology. Circaea 9: 35-47. 
Gobalet, K. W. 2001. A Critique of Faunal Analysis: Inconsistency among Experts in Blind Tests. Journal of Archaeological Science 28:377-386.

Grayson, D. K. 1979. On the Quantification of Vertebrate Archaeofaunas. In Advances in Archaeological Method and Theory 2, edited by M. B. Schiffer, pp. 199237. Academic Press, New York.

Grigson, C. 1978. Towards a Blueprint for Animal Bone Reports in Archaeology. In Research Problems in Zooarchaeology, edited by D. R. Brothwell, K. D.

Thomas, and J. Clutton-Brock, pp. 121-128. Institute of Archaeology Occasional Papers 3.

Horsburgh, K. A. 2008. Wild or Domesticated? An ancient DNA Approach to Canid Species Identification in South Africa's Western Cape Province. Journal of Archaeological Science 35:1474-1480.

Janes, R. R. 1984. Smith-Wintemberg Award. Canadian Journal of Archaeology 8:1-2.

Klein, R. G. and K. Cruz-Uribe. 1984. The Analysis of Animal Bones from Archaeological Sites. University of Chicago Press, Chicago.

Lawrence, B. 1973. Problems in the Inter-site Comparison of Faunal Remains. In Domestikationsforschung und Geschichte der Haustiere, edited by Janos Matolcsi, pp. 397-402. Akademiai Kiadó, Budapest.

Maltby, M. 1981. Iron Age, Romano-British and AngloSaxon Animal Husbandry. A Review of the Faunal Evidence. In The Environment of Man: the Iron Age to the Anglo-Saxon Period, edited by M. Jones and G.

Dimbleby, pp. 155-203. British Archaeological Reports, British Series 87, Oxford.

Nelson, D. E., R. E. Morlan, J.S. Vogel, J.R. Southon and C. R. Harington. 1986. New dates on northern Yukon artifacts: Holocene not Upper Pleistocene. Science 232:749-751.

Tarcan, C. and J. C. Driver. 2010. The Adoption and Use of Domestic Animals at Zuni. In Anthropological Approaches to Zooarchaeology, edited by D. Campana, P. Crabtree, S. D. de France, J. Lev-Tov and A. Choyke, pp. 159-167. Oxbow Books, Oxford.

Walker, D. and G. C. Frison. 1980. The Late Pleistocene Mammalian Fauna from the Colby Mammoth Kill Site, Wyoming. Rocky Mountain Geology 19:69-79.
Yang, D., J. R. Woiderski, and J. C. Driver. 2005. DNA Analysis of Archaeological Rabbit Remains from the American Southwest. Journal of Archaeological Science 32:567-578. 